\title{
Alkali earth co-doping effects on luminescence and scintillation properties of Ce doped $\mathrm{Gd}_{3} \mathrm{Al}_{2} \mathrm{Ga}_{3} \mathrm{O}_{12}$ scintillator
}

\author{
Kei Kamada ${ }^{\mathrm{a}, \mathrm{b}, *}$, Martin Nikl ${ }^{\mathrm{c}}$, Shunsuke Kurosawa ${ }^{\mathrm{a}, \mathrm{d}}$, Alena Beitlerova ${ }^{\mathrm{c}}$, Aya Nagura ${ }^{\mathrm{d}}$, Yasuhiro Shoji ${ }^{\mathrm{b}, \mathrm{d}}$, \\ Jan Pejchal ${ }^{\mathrm{a}, \mathrm{c}}$, Yuji Ohashi ${ }^{\mathrm{d}}$, Yuui Yokota ${ }^{\mathrm{a}}$, Akira Yoshikawa ${ }^{\mathrm{a}, \mathrm{b}, \mathrm{d}}$ \\ a Tohoku University, New Industry Creation Hatchery Center, 6-6-10 Aoba, Aramaki, Aoba-ku, Sendai, Miyagi 980-8579, Japan \\ ${ }^{\mathrm{b}}$ CEA Corporation, T-Biz, 6-6-10 Aoba, Aramaki, Aoba-ku, Sendai, Miyagi 980-8579, Japan \\ 'Institute of Physics AS CR, Cukrovarnicka 10, 16253 Prague, Czech Republic \\ ${ }^{\mathrm{d}}$ Tohoku University, Institute for Material Reseach, 2-1-1 Katahira Aoba-ku, Sendai, Miyagi 980-8577, Japan
}

\section{A R T I C L E I N F O}

\section{Article history:}

Available online 6 November 2014

Keywords:

Scintillator

Garnet

Single crystal growth

\begin{abstract}
A B S T R A C T
The $\mathrm{Mg}$ and $\mathrm{Ca}$ co-doped $\mathrm{Ce}: \mathrm{Gd}_{3} \mathrm{Al}_{2} \mathrm{Ga}_{3} \mathrm{O}_{12}$ single crystals were prepared by micro pulling down method with a wide concentration range $0-1000 \mathrm{ppm}$ of the codopants. Absorption and luminescence spectra were measured together with several other scintillation characteristics, namely the scintillation decay and light yield to reveal the effect of $\mathrm{Mg}$ and $\mathrm{Ca}$ co-doping. The scintillation decays were accelerated by both $\mathrm{Mg}$ and $\mathrm{Ca}$ codopants. Comparing to $\mathrm{Ca}$ co-doping, the $\mathrm{Mg}$ co-doped samples showed much faster decay and comparatively smaller light output decrease with increasing Mg dopant concentration.
\end{abstract}

(c) 2014 Elsevier B.V. All rights reserved.

\section{Introduction}

Scintillator materials combined with photodetectors are used to detect high energy photons and accelerated particles in medical imaging techniques, high energy and nuclear physics detectors, high-tech industrial applications and most recently also in the advanced homeland security related techniques.[1] In the last two decades, great R\&D effort brought several new material systems, namely the Ce-doped orthosilicates as $\mathrm{Gd}_{2} \mathrm{SiO}_{5}$ (GSO), $\mathrm{Lu}_{2-}$ $\mathrm{SiO}_{5}$ (LSO), $\left(\mathrm{Lu}_{1-x} \mathrm{Y}_{x}\right)_{2} \mathrm{SiO}_{5}$ (LYSO), pyrosilicates based on $\mathrm{RE}_{2} \mathrm{Si}_{2} \mathrm{O}_{7}$ $(\mathrm{RE}=\mathrm{Lu}, \mathrm{Y}, \mathrm{Gd})$ and most recently $\mathrm{LaX}_{3}(\mathrm{X}=\mathrm{Cl}, \mathrm{Br})$ single crystal hosts [1-11]. Oxide materials based on garnet structure single crystals are promising candidates for scintillator applications because of well mastered technology developed for laser hosts and other applications, optical transparency and easy doping by rare-earth elements. After a decade of $\mathrm{R} \& \mathrm{D}$ of the $\mathrm{Lu}_{3} \mathrm{Al}_{5} \mathrm{O}_{12}$ (LuAG)-based single crystal scintillators (see review in [12]), new material concept was defined, based on multicomponent $(\mathrm{Gd}, \mathrm{RE})_{3}(\mathrm{Ga}, \mathrm{Al})_{5} \mathrm{O}_{12}$ host, $\mathrm{Re}=\mathrm{Lu}, \mathrm{Y}$. Doped by $\mathrm{Ce}^{3+}$, the $\mathrm{Gd}-$ and Ga rich host compositions showed amazingly high light yield up to almost 50,000 phot/MeV [13-16] which is the value exceeding by $30-40 \%$ the best Ce:LYSO materials ever seen. Recently, our group reported about $\mathrm{Ce}: \mathrm{Gd}_{3} \mathrm{Al}_{2} \mathrm{Ga}_{3} \mathrm{O}_{12}$ (GAGG) single crystal and

* Corresponding author at: Tohoku University, New Industry Creation Hatchery Center, 6-6-10 Aoba, Aramaki, Aoba-ku, Sendai, Miyagi 980-8579, Japan. scintillation response of about $\sim 90 \mathrm{~ns}$ at emission around $520 \mathrm{~nm}$, excellent light yield of about 56,000 photon/MeV, and density of $6.63 \mathrm{~g} / \mathrm{cm}^{3}[15,16]$. In the silicate, perovskite and garnet scintillators the slow tunneling-driven radiative recombination between Ce emission centers and nearby lying electron traps can deteriorate scintillation performance $[12,17]$. Ce:LSO and Ce:LYSO single crystals co-doped with $\mathrm{Ca}^{2+}$ have been recently investigated and improvement in their scintillation characteristics, namely afterglow suppression and scintillation decay acceleration, were claimed[18,19] which is based on the suppression of such slow delayed recombination processes. Positive role of stable $\mathrm{Ce}^{4+}$ centers has been proposed in [19] to explain the improved scintillation performance. Very recently, such an approach has been used in Mg-codoped Ce:LuAG scintillation ceramics the light yield of which was enormously enhanced and the presence of $\mathrm{Ce}^{4+}$ was clearly identified by its characteristic charge transfer (CT) absorption in the near UV range below $350 \mathrm{~nm}$ [20]. On the contrary, strong degradation of light yield due to $\mathrm{Ca}^{2+}$ co-doping in Ce:GAGG has been recently reported [21].

The aim of this work is to investigate and compare the alkali earth $\left(\mathrm{AE}, \mathrm{AE}^{2+}=\mathrm{Mg}^{2+}, \mathrm{Ca}^{2+}\right)$ co-doping effects on luminescence and scintillation properties of Ce:GAGG scintillator. In this report, AE co-doped Ce:GAGG single crystal were grown by the micropulling down ( $\mu$-PD) method and characterized as for the chemical composition. Luminescence and scintillation characteristics were also measured. 


\section{Experimental}

\subsection{Crystal growth}

A stoichiometric mixture of $4 \mathrm{~N} \mathrm{MgCO}_{3}, \mathrm{CaCO}_{3}, \mathrm{CeO}_{2}, \alpha-\mathrm{Al}_{2} \mathrm{O}_{3}$, $\mathrm{Ga}_{2} \mathrm{O}_{3}$ and $\mathrm{Gd}_{2} \mathrm{O}_{3}$, powders (High Purity Chemicals Co.) was used as starting material. Nominally, starting powders were prepared according to the formula of $\left(\mathrm{AE}_{x}, \mathrm{Ce}_{y}, \mathrm{Gd}_{1-y}\right)_{3} \mathrm{Al}_{2} \mathrm{Ga}_{3} \mathrm{O}_{12}\left(\mathrm{CO}_{3}\right)_{x}$. Single crystals of $\mathrm{AE}(=\mathrm{Mg}, \mathrm{Ca})$ co-doped $\mathrm{Ce}$ :GAGG were grown by the $\mu$-PD method with an RF heating system. The $y$ was 0.005 and $x$ were $0,0.0001,0.00020 .0005$ and 0.001 . These samples will be noted as $\mathrm{Mg}$ or Ca-0, 100, 200, 500 and 1000. A schematic of the $\mu$-PD growth apparatus is given in Ref. [22]. Typical pulling rates were $0.05-0.07 \mathrm{~mm} / \mathrm{min}$ and the diameter was around $3 \mathrm{~mm}$. Crystals were grown from an Ir crucible under the $\mathrm{N}_{2}$ atmosphere. The seed crystals were $\langle 100\rangle$ oriented Ce:GAGG crystals. Plates of $\emptyset 3 \mathrm{~mm} \times 1 \mathrm{~mm}$ were cut and polished for the absorption and luminescence spectra measurements, while the rest of the rods were used for the chemical composition analyses. Quantitative chemical analyses of the crystals for the $\mathrm{Mg}$, $\mathrm{Ce}, \mathrm{Al}, \mathrm{Ga}$ and $\mathrm{Gd}$ content along the radius and growth direction were performed by the electron probe micro-analysis (EPMA; JXA-8621MX, JEOL). So called $Z A F$ correction is used, where $Z, A$ and $F$ are the atomic number, absorption correction factor and fluorescence correction factor, respectively. X-ray Fluorescence Analysis (XRF) was also performed to determine chemical composition of grown crystals by Rigaku ZSX primus II.

\subsection{Optical, luminescence and gamma-ray response measurement procedure}

Absorption spectra were measured by the Shimadzu 3101PC spectrometer in the $190-1200 \mathrm{~nm}$ range. At the custom made $5000 \mathrm{M}$ model fluorometer Horiba Jobin Yvon equipped with the photon counting detector TBX-04 (IBH Scotland) the

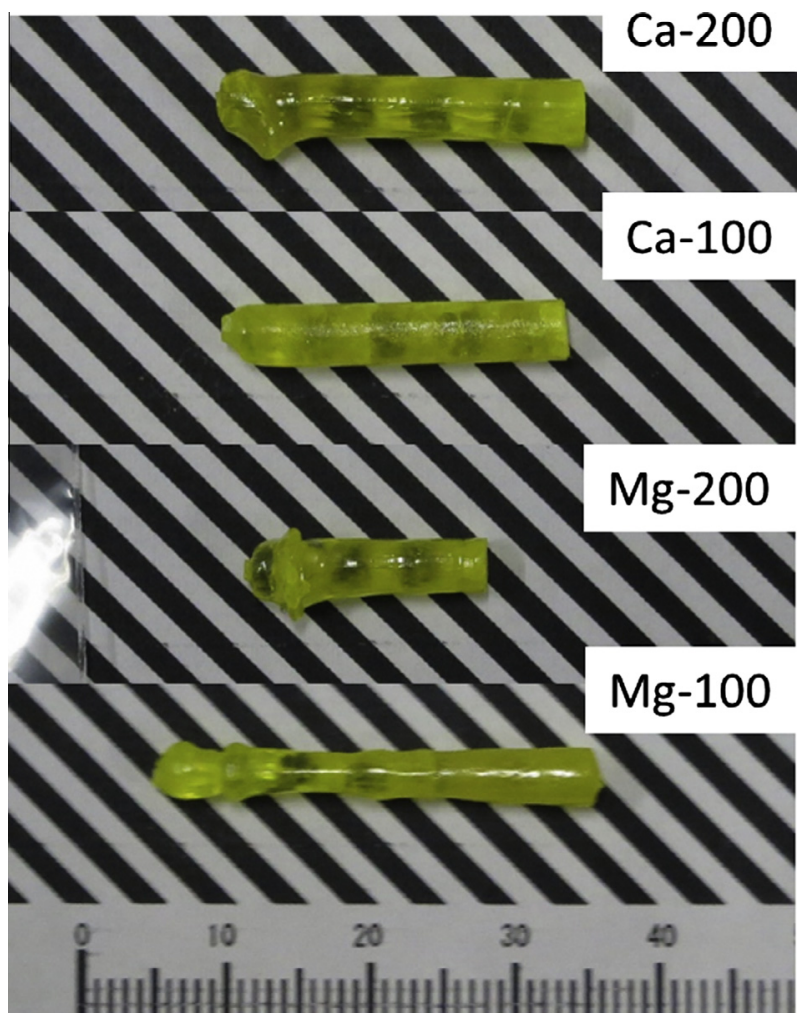

Fig. 1. Example photos of the grown AE co-doped Ce:GAGG crystals.

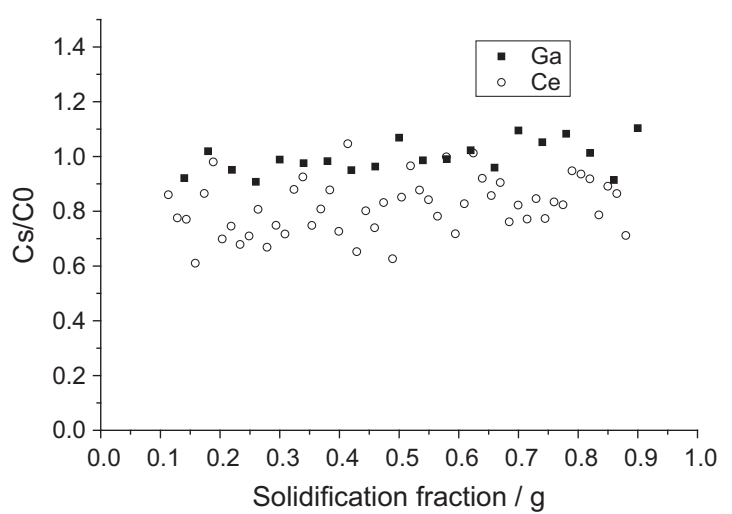

Fig. 2. The Ce distribution along growth direction of the Ca $1000 \mathrm{ppm}$ co-doped Ce0.5\%:GAGG crystal.

radioluminescence (RL) spectra were measured under an X-ray ( $40 \mathrm{kV}, 10 \mathrm{~mA}$ ) tube (Seifert $\mathrm{Gmbh}$ ) and the nanoLED $450 \mathrm{~nm}$ excitation sources, respectively. Light output measurements were performed by using photomultiplier tube (PMT Hamamatsu R7600U). Sample pieces with dimensions of $\emptyset 3 \times 1 \mathrm{~mm}$ were cut from the grown single crystal, $\varnothing 3 \mathrm{~mm}$ surfaces were mechanically polished. The samples were coupled by the PMT using silicone grease (OKEN, $6262 \mathrm{~A}$ ). The pieces were covered by using Teflon-tape. To determine the light yield, the energy spectra were collected under $662 \mathrm{keV} \gamma$-ray excitation $\left({ }^{137} \mathrm{Cs}\right.$ source) by using a PMT (Hamamatsu H7600, bialkali photocathode, quartz window). The signal was fed into a shaping amplifier (ORTEC 572A), a multichannel analyzer (MCA) (ORTEC 926), and finally to a personal computer. The shaping time was set as $2 \mu$ s. The bias for the PMT was supplied by an
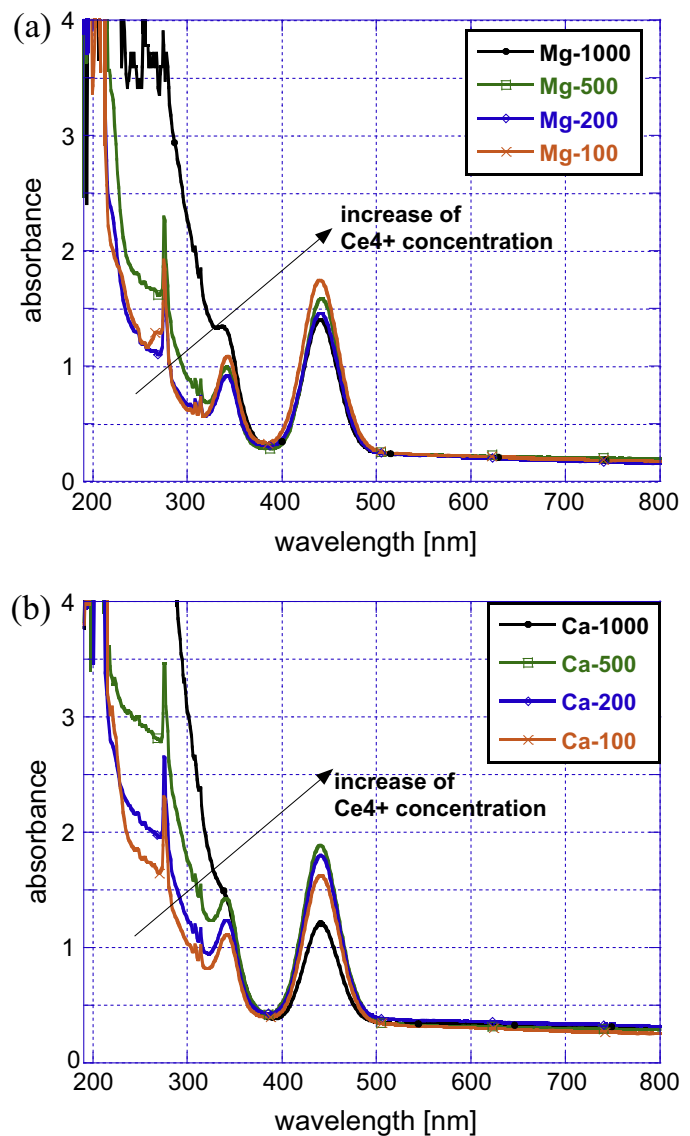

Fig. 3. Absorption spectra of the (a) Mg and (b) Ca co-doped Ce:GAGG crystals. 

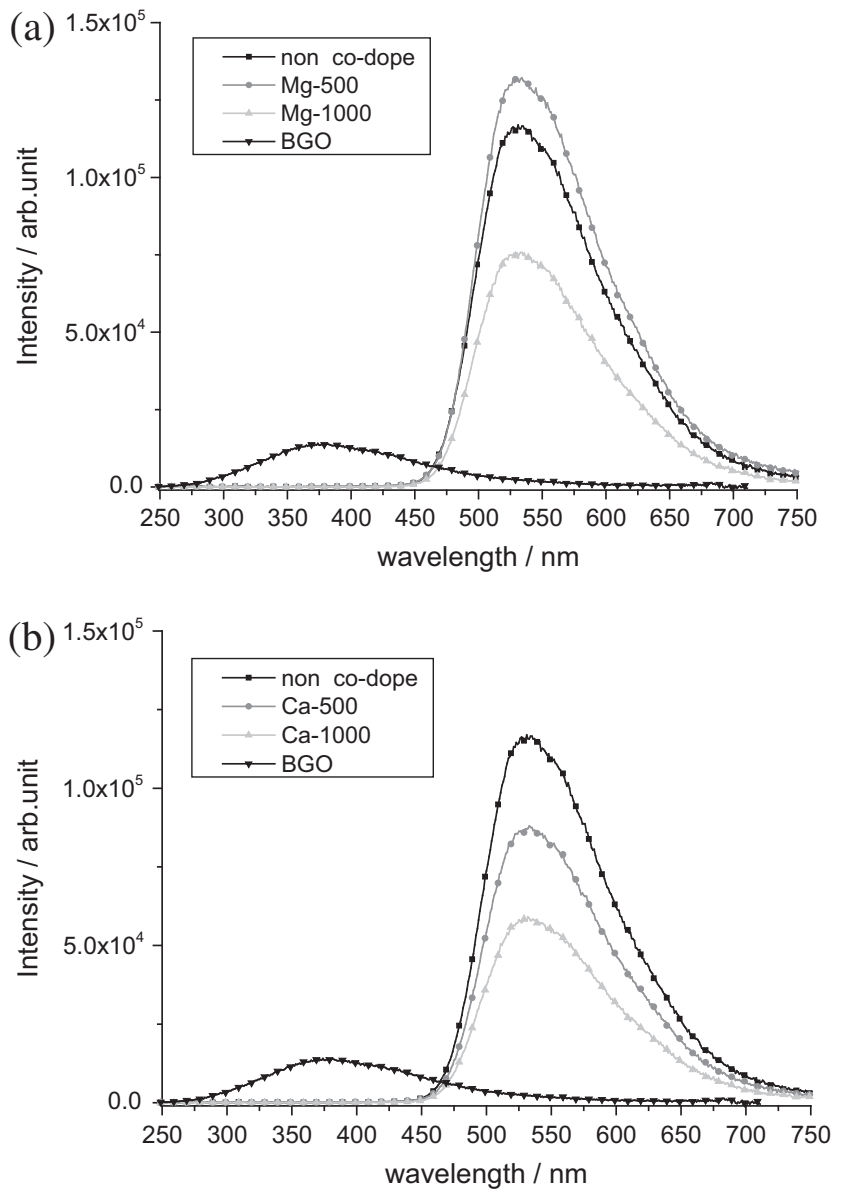

Fig. 4. Radioluminescence spectra of the (a) Mg and (b) Ca co-doped Ce:GAGG crystals. Excitation by X-rays, $40 \mathrm{kV}, 15 \mathrm{~mA}$.

ORTEC 556. For the decay time measurement the same setup with the PMT and digital oscilloscope TD5032B were used.

\section{Result and discussion}

\subsection{Crystal growth}

$\mathrm{Mg}$ and Ca co-doped Ce0.5\%:GAGG crystals were grown by the $\mu$-PD method. Example photos are shown in Fig. 1. The grown crystals were transparent with yellow color and $2-3 \mathrm{~mm}$ in diameter, $15-30 \mathrm{~mm}$ in length. Some of them look slightly cloudy because of the rough surface coming from the gallium oxide evaporation and thermal etching. However, the inner part of all the crystals is perfectly transparent.

Chemical composition distribution along growth direction of $\mathrm{Ca}$ 1000 ppm co-doped Ce0.5\%:GAGG measured by EPMA is shown in Fig. 2. Ca could not be detected by EPMA. The effective segregation coefficients of Ce and Ga ions showed $k_{\text {eff }}=0.793$ and 0.965 values, respectively. XRF measurement was performed on the $\mathrm{Ca}$ $1000 \mathrm{ppm}$ co-doped sample and $\mathrm{Ca}$ concentration was 1667 at. ppm. EPMA and XRF were also performed on the $\mathrm{Mg}$ 1000 ppm co-doped sample, but Mg could not be detected. Most probably its actual concentration in $\mathrm{Mg}$ co-doped samples is below the detection limit of XRF (Mg: 2000 at. ppm).

\subsection{Optical and luminescence properties}

The absorption spectra of the sample set are presented in Fig. 3. In addition of the $4 \mathrm{f}-5 \mathrm{~d}_{1,2}$ absroption bands of $\mathrm{Ce}^{3+}$ center at 450

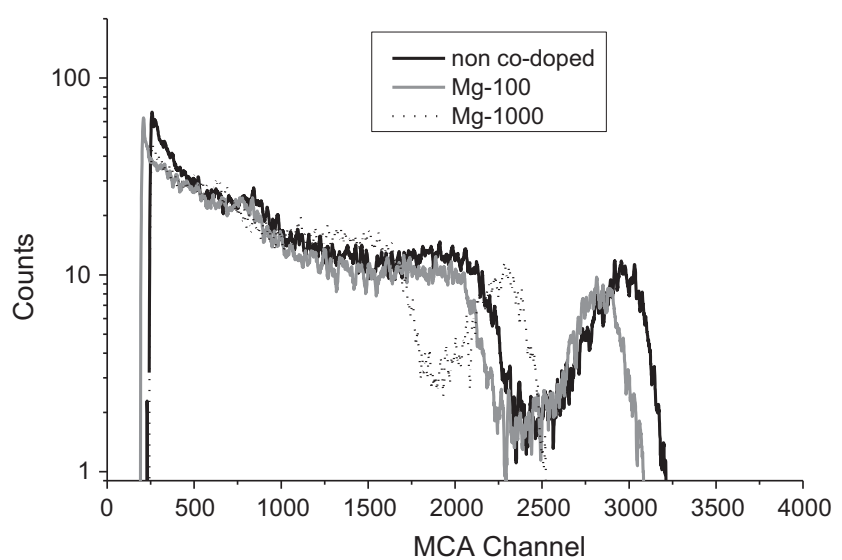

Fig. 5. Energy spectra of the Mg co-doped Ce:GAGG crystals. Excitation by $137 \mathrm{Cs}$ radioisotope (662 keV).

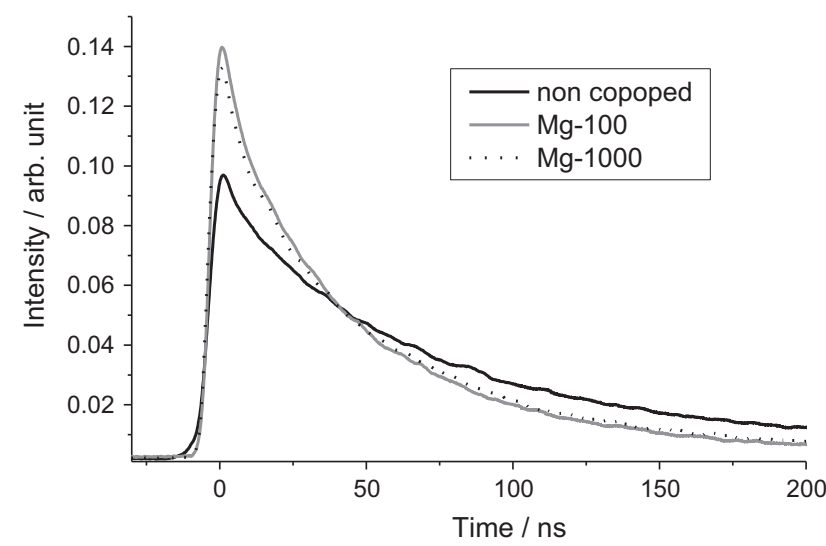

Fig. 6. Scintillation decay curves of the Mg co-doped Ce:GAGG crystals. Excitation by 137 Cs radioisotope (662 keV).

and $340 \mathrm{~nm}$, respectively, the $\mathrm{Ce}^{4+} \mathrm{CT}$ absorption below $350 \mathrm{~nm}$ is clearly enhanced with increasing concentration of $\mathrm{Mg}$ and $\mathrm{Ca}$ co-dopant, similarly to what was observed in [20]. Radioluminescence (RL) spectra in Fig. 4a show an enhancement of the $\mathrm{Ce}^{3+}$ emission band at $520 \mathrm{~nm}$ between the Mg-0 and Mg-500 samples. With further increasing $\mathrm{Mg}$ concentration its intensity decreases. In the case of Ca co-doping, the $\mathrm{Ce}^{3+}$ emission intensity is smoothly decreasing with increasing Ca concentration (Fig. 4b).

\subsection{Gamma-ray response}

The typical energy spectra of Mg co-doped Ce:GAGG excited by ${ }^{137} \mathrm{Cs}$ at room temperature and measured using the PMT are shown in Fig. 5. Light output was decreased with increasing Mg concentrations. Light output of the $\mathrm{Mg} 100 \mathrm{ppm}$ sample was around $94 \%$ of non co-doped sample. Scintillation decay curves were observed by using digital oscilloscope TD5032B under the excitation by ${ }^{137} \mathrm{Cs}$ radioisotope $(662 \mathrm{keV})$. Scintillation decay curves of $\mathrm{Mg}$ co-doped Ce:GAGG crystals were shown in Fig. 6. Under the same experimental conditions, the scintillation decay amplitude of $\mathrm{Mg}$ $100 \mathrm{ppm}$ sample was 1.5 times higher than that of non-codoped sample. The scintillation decay curves were accelerated by $\mathrm{Mg}$ co-doping and decay time value decreased down to 39 ns. Table 1 shows the survey of light yield and scintillation decay time values. Comparing to Ca co-doping, Mg co-doped samples showed faster decay even at low $\mathrm{Mg}$ concentration and almost the same light output was measured in the $\mathrm{Mg} 100 \mathrm{ppm}$ sample in comparison with the Mg-free sample. 
Table 1

Light yield and scintillation decay time values of the Mg and Ca co-doped Ce:GAGG crystals. Scintillation decay is approximated by the sum of two exponentials $\left.I(t)=A_{i} \exp [-t)_{i}\right], i-1,2$. Ratio (\%) is calculated as $A_{11} /\left(A_{11}+A_{22}\right) \times 100 \%$ for the first component.

\begin{tabular}{llll}
\hline $\begin{array}{l}\text { AE concentration } \\
(\text { at. ppm for } \mathrm{Gd})\end{array}$ & $\begin{array}{l}\text { Light output }(\% \\
\text { for } \mathrm{AE}=0))\end{array}$ & $\begin{array}{l}\text { 1st decay time } \\
(\mathrm{ns}) / \text { ratio }(\%)\end{array}$ & $\begin{array}{l}\text { 2nd decay time } \\
(\mathrm{ns}) / \text { ratio(\%) }\end{array}$ \\
\hline 0 & 100 & $61.5 / 52$ & $225 / 48$ \\
$\mathrm{Mg}-100$ & 94 & $39.6 / 53$ & $132 / 47$ \\
$\mathrm{Mg}-200$ & 86 & $39.7 / 50$ & $140 / 50$ \\
$\mathrm{Mg}-500$ & 87 & $39.8 / 49$ & $144 / 51$ \\
$\mathrm{Mg}-1000$ & 76 & $39.5 / 55$ & $131 / 45$ \\
$\mathrm{Ca}-100$ & 87 & $51.1 / 51$ & $248 / 49$ \\
$\mathrm{Ca}-200$ & 86 & $51.4 / 60$ & $205 / 40$ \\
$\mathrm{Ca}-500$ & 72 & $42.5 / 70$ & $147 / 30$ \\
$\mathrm{Ca}-1000$ & 56 & $39.7 / 58$ & $137 / 42$ \\
\hline
\end{tabular}

The obtained results can be interpreted in an analogous way as it has been done in the Ce-doped orthosilicate LYSO [19] and aluminum garnet LuAG [20]. Stabilization of $\mathrm{Ce}^{4+}$ center provides an alternative fast radiative de-excitation channel: after the capture of an electron from conduction band at such a $\mathrm{Ce}^{4+}$ center the excited $\mathrm{Ce}^{3+}$ ion is formed and scintillation photon in the $520 \mathrm{~nm}$ band is emitted immediately. The $\mathrm{Ce}^{4+}$ center thus effectively competes with electron traps of any kind in the material for the electron capture and contributes to the fastest component of scintillation response. The decrease of the overall scintillation efficiency (radioluminescence intensity) observed at higher $\mathrm{Mg}$ concentrations requires further study for full understanding.

\section{Conclusion}

The $\mathrm{Mg}$ and Ca-codoped Ce0.5\%:GAGG single crystals were grown by the micro pulling down method and their optical, luminescence and scintillation characteristics were measured. The intensity enhancement of the $\mathrm{Ce}^{3+}$ emission band at $520 \mathrm{~nm}$ in radioluminescence spectra was observed between the Mg-0 and Mg-500 samples. The scintillation decays were accelerated by $\mathrm{Mg}$ co-doping and dominant decay time decreased down to $39 \mathrm{~ns}$. Comparing to Ca co-doping, the Mg co-doped samples showed better figure of merit due to shorter decay time values and only less decreasing light output with increasing $\mathrm{Mg}$ concentration. Timing characteristics of Ce:GAGG could be thus improved by $\mathrm{Mg}$ co-doping. These results indicate that $\mathrm{Mg}$ co-doped $\mathrm{Ce}$ :GAGG can be promising scintillator for application which require fast timing resolution such as positron emission tomography. In the near future we will report about the bulk crystal growth of Mg co-doped Ce:GAGG by Czochralski method. Scintillation response improvement is expected due to much higher quality of Czochralski-grown crystal samples.

\section{Acknowledgements}

This work is partially supported by (i) the funding program for next generation world-leading researchers, Japan Society for the Promotion of Science (JSPS), (ii) Development of Systems and Technology for Advanced Measurement and Analysis, Japan Science and Technology Agency (JST) (iii) Adaptable \& Seamless Technology Transfer Program through Target-driven R\&D (A-STEP), JST (iv) JSPS
Grant-in-Aid for Exploratory Research (A.Y), (v) JSPS Research Fellowships for Young Scientists (S.Kurosawa), (vi) the Health Labour Sciences Research Grant, The Ministry of Health Labour and Welfare and (vii) Czech MEYS KONTAKT Cz-jp collaboration LH14266 project, Crystal Clear Collaboration in CERN, and EC Marie Curie Initial Training Network LUMINET, no. 316906. In addition, we would like to thank following persons for their support: Mr. Yoshihiro Nakamura in Institute of Multidisciplinary Research for Advanced Materials (IMRAM), and Mr. Hiroshi Uemura, Ms. Keiko Toguchi, Ms. Megumi Sasaki and Ms. Yuka Takeda in IMR, Tohoku University.

\section{References}

[1] M. Nikl, Scintillation detectors for X-rays, Meas. Sci. Technol. 17 (February) (2006) R37-R54

[2] C.L. Melcher, J.S. Schweitzer, Cerium-doped lutetium orthosilicate: a fast, efficient new scintillator, IEEE Trans. Nucl. Sci. 39 (4) (1992) 502-505.

[3] M. Kapusta, P. Szupryczynski, C.L. Melcher, M. Moszynski, M. Balcerzyk, A.A. Carey, et al., Nonproportionality and thermoluminescence of LSO:Ce, IEEE Trans. Nucl. Sci. 52 (4) (2005) 1098-1104.

[4] M.A. Spurrier, P. Szupryczynski, A.A. Carey, C.L. Melcher, Effects of $\mathrm{Ca}^{2+} \mathrm{CO}^{-}$ doping on the scintillation properties of LSO:Ce, IEEE Trans. Nucl. Sci. NS-55 (3) (2008) 1178-1182.

[5] P. Lecoq, M. Korzhik, New inorganic scintillation materials development for medical imaging, IEEE Trans. Nucl. Sci. 49 (4) (2002) 1651-1654.

[6] M. Moszynski, D. Wolski, T. Ludziejewski, M. Kapusta, A. Lempicki, C. Brecher et al., Properties of the new LuAP:Ce scintillator, Nucl. Instrum. Methods A 385 (Jan. 1997) 123-131.

[7] S. Weber, D. Christ, M. Kurzeja, R. Engels, G. Kemmerling, H. Halling, Comparison of LuYAP, LSO, BGO as scintillators for high resolution PET detectors, IEEE Trans. Nucl. Sci. 50 (5) (2003) 1370-1372.

[8] M. Conti, State of the art and challenges of time-of-flight PET, Phys. Med. 25 (2009) $1-11$

[9] K.S. Shah, J. Glodo, M. Klugerman, W.W. Moses, S.E. Derenzo, M.J. Weber, $\mathrm{LaBr}_{3}$ :Ce scintillators for gamma-ray spectroscopy, IEEE Trans. Nucl. Sci. 50 (6) (Dec. 2003) 2410-2413.

[10] K.W. Kramer, P. Dorenbos, H.U. Gudel, C.W.E. van Eijk, Development and characterization of highly efficient new cerium doped rare earth halide scintillator materials, J. Mater. Chem. 16 (2006) 2773-2780.

[11] M.S. Alekhin, J.T.M. de Haas, I.V. Khodyuk, K.W. Kramer, P.R. Menge, V. Ouspenski, P. Dorenbos, Improvement of $\gamma$-ray energy resolution of $\mathrm{LaBr}_{3}: \mathrm{Ce}^{3+}$ scintillation detectors by $\mathrm{Sr}^{2+}$ and $\mathrm{Ca}^{2+}$ co-doping, Appl. Phys. Lett. 102 (2013) 161915.

[12] M. Nikl, A. Yoshikawa, K. Kamada, K. Nejezchleb, C.R. Stanek, J.A. Mares, K. Blazek, Development of LuAG-based scintillator crystals - a review, Prog. Cryst. Growth Charact. Mater. 59 (2013) 47-72.

[13] N.J. Cherepy, J.D. Kuntz, Z.M. Seeley, S.E. Fisher, O.B. Drury, B.W. Sturm, et al., Proc. SPIE 7805 (2010) 780501-780505.

[14] K. Kamada, T. Endo, K. Tsutumi, T. Yanagida, Y. Fujimoto, A. Fukabori, et al., Cryst. Growth Des. 11 (2011) 4484-4490.

[15] K. Kamada, T. Yanagida, T. Endo, K. Tsutumi, Y. Usuki, M. Nikl, et al., J. Cryst. Growth 352 (2012) 88-90.

[16] K. Kamada, P. Pursa, M. Nikl, V.V. Kochurikhin, T.i. Endo, K. Tsutumi, H. Sato, S Kurosawa, Y. Yokota, K. Sugiyama, A. Yoshikawa, Opt. Mater. 36 (12) (2014) $1942-1945$.

[17] M. Nikl, A. Vedda, G.P. Pazzi, E. Mihokova, M. Fasoli, J. Pejchal, P. Bohacek, A Yoshikawa, G. Ren, K. Nejezchleb, Tunnelling processes-driven radiative recombination in complex oxide scintillators, J. Phys: Conf. Ser. 249 (2010) 012018.

[18] M.A. Spurrier, P. Szupryczynski, K. Yang, A.A. Carey, C.L. Melcher, IEEE Trans. Nucl. Sci. 55 (2008) 1178-1182.

[19] S. Blahuta, A. Bessiere, B. Viana, P. Dorenbos, V. Ouspenski, IEEE Trans. Nucl. Sci. 60 (2013) 3134-3141.

[20] S. Liu, X. Feng, Z. Zhou, M. Nikl, Y. Shi, Y. Pan, Phys. Stat. Sol. RRL 8 (2014) 105 109.

[21] S.B. Donnald, M. Tyagi, H. Rothfuss, F. Meng, J.P. Hayward, M. Koschan, C.L. Melcher, IEEE Trans. Nucl. Sci. 60 (5) (2013) 4002-4006.

[22] A. Yoshikawa, B.M. Epelbaum, K. Hasegawa, S.D. Durbin, T. Fukuda, Microstructures in oxide eutectic fibers grown by a modified micro-pullingdown method, J. Cryst. Growth 205 (Sep. 1999) 305-316. 